\title{
The identification of Bradyrhizobium japonicum strains isolated from Italian soils
}

\author{
1 School of Biological \\ Sciences, University of \\ Bristol, Woodland Road, \\ Bristol BS8 1UG, UK \\ 2 ICI Seeds - SES NV/SA, \\ Industriepark 15, B-3300 \\ Tienen, Belgium \\ 3 Department of \\ Microbiology, University of \\ Newcastle-upon-Tyne, The \\ Medical School, \\ Framlington Place, \\ Newcastle-upon-Tyne \\ NE2 $4 \mathrm{HH}$, UK \\ 4 Department of Biological \\ Sciences, University of \\ Wales, Aberystwyth, Dyfed \\ SY23 3DA, UK \\ 5 Dipartimento di \\ Biotecnologie Agrarie, \\ Universita di Padova, Via \\ Gradenigo, 6-35131 \\ Padova, Italy \\ 6 Heligenetics SpA, Via \\ Provinciale 12, Gaiba, \\ Rovigo, Italy
}

\author{
H. E. Kay, ${ }^{1}$ H. L. C. Coutinho, ${ }^{1} \dagger$ M. Fattori, ${ }^{2}$ G. P. Manfio, ${ }^{3}+$ R. Goodacre, ${ }^{4}$ \\ M. P. Nuti, ${ }^{5}$ M. Basaglia ${ }^{6}$ and J. E. Beringer ${ }^{1}$
}

Author for correspondence: John E. Beringer. Tel: +44 272 303759. Fax: +44 272257374.

\begin{abstract}
Pyrolysis mass spectrometry (PYMS) and PCR using arbitrary primers were used to characterize strains of Bradyrhizobium japonicum isolated from fields in northern Italy. The combination of techniques allowed us to identify bacteria derived from inoculants and to demonstrate that information about the nature of one inoculant was incorrect. PYMS also indicated that the derivatives from one inoculant formed two distinct populations: one like the parent strain and the other altered phenotypically.
\end{abstract}

Keywords: Bradyrbizobium japonicum, pyrolysis mass spectrometry, polymerase chain reaction, strain identification, soil bacteria

\section{INTRODUCTION}

Leguminous crop plants have been inoculated with strains of Rbiobium and Bradyrhizobium since the turn of the century in order to improve their growth in soils which do not contain appropriate species of these bacteria. Much effort has been put into developing simple and reliable techniques for identifying isolates from soils so that the fate of inoculants can be determined and plant responses can be related to the bacteria forming the nodules (Dudman, 1971; Mielenz et al., 1979; Kamicker \& Brill, 1986; Hartmann et al., 1992).

Recently there has been considerable interest in studies of the survival of organisms released to the environment because of the development and intended use of genetically modified organisms. This has increased the

†Present address: Fundação Tropical de Pesquisas e Technologia André Tosello, Rua Latino Coelho 1301, Campinas-SP 13087-010, Brazil.

Abbreviations: MPN, most probable number; PYMS, pyrolysis mass spectrometry; RAPD, randomly amplified polymorphic DNA. need for good methods to study soil populations of bacteria. We decided to take advantage of the introduction of a new legume crop, soybeans, to Italy to initiate studies of the fate of non-indigenous bacteria released into soils. Bradyrbizobium japonicum strains capable of nodulating soybeans must be introduced to allow nodule formation. Because few inoculants have been used, and we have access to the strains used in them, we are in a position to look at specific fields and see what has happened to the strains that were introduced.

In order to facilitate these studies we have used two techniques that have only recently become available for ecological studies. These are pyrolysis mass spectrometry (PYMS) and the use of the polymerase chain reaction (PCR). With PCR we fingerprint strains using arbitrary primers annealing at low stringency to the template DNA, producing fragments of DNA from the regions between closely spaced primers (RAPD; Williams et al., 1990).

PYMS is a procedure in which samples from colonies are thermally degraded under vacuum (pyrolysis). Fragments produced are ionized and then analysed by a mass 
spectrometer. Using multivariate analysis the proportions of different mass classes are used to discriminate strains (Gutteridge, 1987; Goodacre et al., 1991b). This technique is able to discriminate derivatives of the same strairı of Escherichia coli which do, or do not, have fimbriae (Goodacre et al., 1991a), or which carry different plasmids (Goodacre \& Berkeley, 1990). The great advantage of this technique is that it characterizes strains on the basis of their phenotype and thus should be able to detect genetic drift, even though the number of base pair differences between strains is very small. In this respect it has been used to study fossil material (Meuzelaar et al., 1982).

RAPD is a fingerprinting system based on the genotype because the bands produced reflect the presence of short sequences of DNA having sufficient homology with the primers used to enable in vitro DNA synthesis under lowstringency annealing conditions. With this technique derivatives of the same strain are unlikely to be discriminated because the chance that the priming sites share the same DNA sequence is very high.

\section{METHODS}

Isolation of bradyrhizobia. In 1990 about 100 nodules were selected at random from roots of soybeans nodulated by resident bradyrhizobia in a field near Udine (field A) and near Perugia (field B). Nodules were surface-sterilized and bradyrhizobia were isolated by streaking liquid from crushed nodules on YMA plates to produce single colonies. Once colonies had formed, the YMA plates were posted to Bristol and the bacteria were frozen at approximately $-20{ }^{\circ} \mathrm{C}$ in $20 \%(\mathrm{v} / \mathrm{v})$ glycerol by taking a loopful of culture from a Petri dish and emulsifying it directly in the glycerol. When required for analysis, samples from glycerol were cultured once on YMA agar and were incubated at $28{ }^{\circ} \mathrm{C}$ for $510 \mathrm{~d}$ on PSY agar.

Standard strains of B. japonicum. Strain CB1809 is used worldwide in inoculants. We also used strain NPPL, which is an isolate of CB1 809 obtained by us from an inoculant produced by New Plant Products Ltd, Cambridge, UK, as a control strain to monitor the reproducibility of our assay techniques. Strain USDA110, like CB1809, is a 'well-known' B. japonicum strain. The cultures used as standards in this study were from cur laboratory culture collections. They were maintained routinely on YMA, with incubation at $28^{\circ} \mathrm{C}$.

Two inoculants were used in the sites we studied: Nitragin and Azofix. The Nitragin inoculum (obtained from Helibioagri, Gaiba, Rovigo, Italy) contained six different B. japonicum strains: $61 \mathrm{~A} 101_{\mathrm{e}}, 61 \mathrm{~A} 148,61 \mathrm{~A} 212,61 \mathrm{~A} 118_{\mathrm{b}}, 61 \mathrm{~A} 152$ and $61 \mathrm{~A} 12 \mathrm{t}_{\mathrm{a}}$, which we have named I1-I6 respectively. Azofix is a singlestrain inoculant and was obtained from SES, Massa Lombarcla, Italy. We isolated B. japonicum from the Azofix inoculant which was marketed prior to 1986 and call the strain Azo, which should be identical to USDA110. Having completed the research we were informed by Dr P. Rubboli (SES, Massa Lombarda, Italy) that the Azofix inoculant was formulated with B. japonicum strain USDA110 up to 1986, and from then strain CB1809 was substituted.

Medium. YMA is yeast-extract mannitol agar. It was prepared as described by Beringer et al. (1984) and was used for routine culturing of B. japonicum strains. PSY is peptone salts yeast and was used for the growth of colonies for RAPD and PYMS analysis because they produce less polysaccharide, which interferes with these assays, on this medium. It was prepared as described by Regensburger \& Hennecke (1983).
Most probable number (MPN) counts. These were done in triplicate for each sample according to the procedure recommended by Vincent (1970) using Leonard jars in a glasshouse, with the soybean as host plant. Soils were sampled just before soybeans were sown in 1989.

PYMS of B. japonicum cultures. A Horizon Instruments PYMS $200 \mathrm{X}$ machine was used (Horizon Instruments, Heathfield, East Sussex, UK; Aries et al., 1986), at the Mass Spectrometry Unit, University of Newcastle-upon-Tyne and the Department of Biological Sciences, University of Wales, Aberystwyth. Materials for PYMS, such as sample glass tubes, Curie-point foils and Viton O-rings were supplied by Horizon Instruments. The foils had a nickel:iron ratio of 50:50, which produced a pyrolysis temperature of $530^{\circ} \mathrm{C}$.

Clean foils were inserted into pyrolysis tubes, so that about twothirds of the foil was protruding from the mouth of the tube. After incubation ( $7 \mathrm{~d}$ ), bacteria were picked up carefully from the top of a colony, avoiding the agar surface, by means of disposable plastic loops and smeared on the exposed foil to give a thin uniform surface coating. All bacteria for one analysis were cultured for the same length of time. Three samples for analysis were taken from each plate. The samples were oven dried at $80{ }^{\circ} \mathrm{C}$ for $5 \mathrm{~min}$, then the foils were pushed into the tubes using a stainless steel depth gauge so as to lie $10 \mathrm{~mm}$ from the mouth of the tube. Finally, Viton ' $\mathrm{O}$ '-rings were placed on the tubes.

The bacterial samples were processed by the machine autosampler. Individual tubes were heated to $80^{\circ} \mathrm{C}$ for a few seconds under vacuum before pyrolysis. Curie-point pyrolysis was at $530{ }^{\circ} \mathrm{C}$ for $2.4 \mathrm{~s}$, with a temperature rise time of $0.5 \mathrm{~s}$. The pyrolysate then entered a gold-plated expansion chamber heated to $140^{\circ} \mathrm{C}$, whence it diffused down a molecular beam tube to the ionization chamber of the mass spectrometer. Low-voltage electron-impact ionization $(25 \mathrm{eV})$ was used to ionize the pyrolysate, which was then focussed by the electrostatic lens of a set of source electrodes, accelerated and directed into a quadrupole mass filter. The ions were separated by the quadrupole on the basis of their mass-to-charge $(\mathrm{m} / \mathrm{z})$ ratio, and detected and amplified with an electron multiplier. The mass spectrometer scans the ionized pyrolysate of mass between 50 and 200 over $20 \mathrm{~s}$. The IBM-compatible personal computer used to control the PYMS-200X was also programmed (using software provided by the manufacturers) to record spectral information on ion count for the individual masses scanned and the total ion count for each sample analysed.

Only samples whose total ion counts were between $5 \times 10^{5}$ and $6 \times 10^{6}$ were used so that pyrolysis mass spectra were representative of the sample. It is considered that if total ion counts below $5 \times 10^{5}$ are observed, too little sample was analysed; above $6 \times 10^{6}$, saturation effects can be seen in spectra and catalytic effects or heat transfer problems may have occurred during pyrolysis (Windig et al., 1979). Finally, data were normalized by an iterative procedure to remove the effect of sample size differences and sorted by charactericity, which is based on the masses produced. Masses are ranked on the basis of their pre-determined importance. For each mass the programme looks at masses showing most variance between groups (replicates), but least within the group. The 30 most characteristic masses were subjected to further statistical analysis.

The statistical analysis of the data was performed using GENSTAT version $\mathrm{V}$, using the program codes provided by Horizon Instruments with the software PYMENu. The method of data analysis has been described by MacFie \& Gutteridge (1982) and Gutteridge et al. (1985). In essence, the first stage was the reduction of the data by principal-components analysis (PCA) (Chatfield \& Collins, 1980; Causton, 1987; Gutteridge, 1987; 


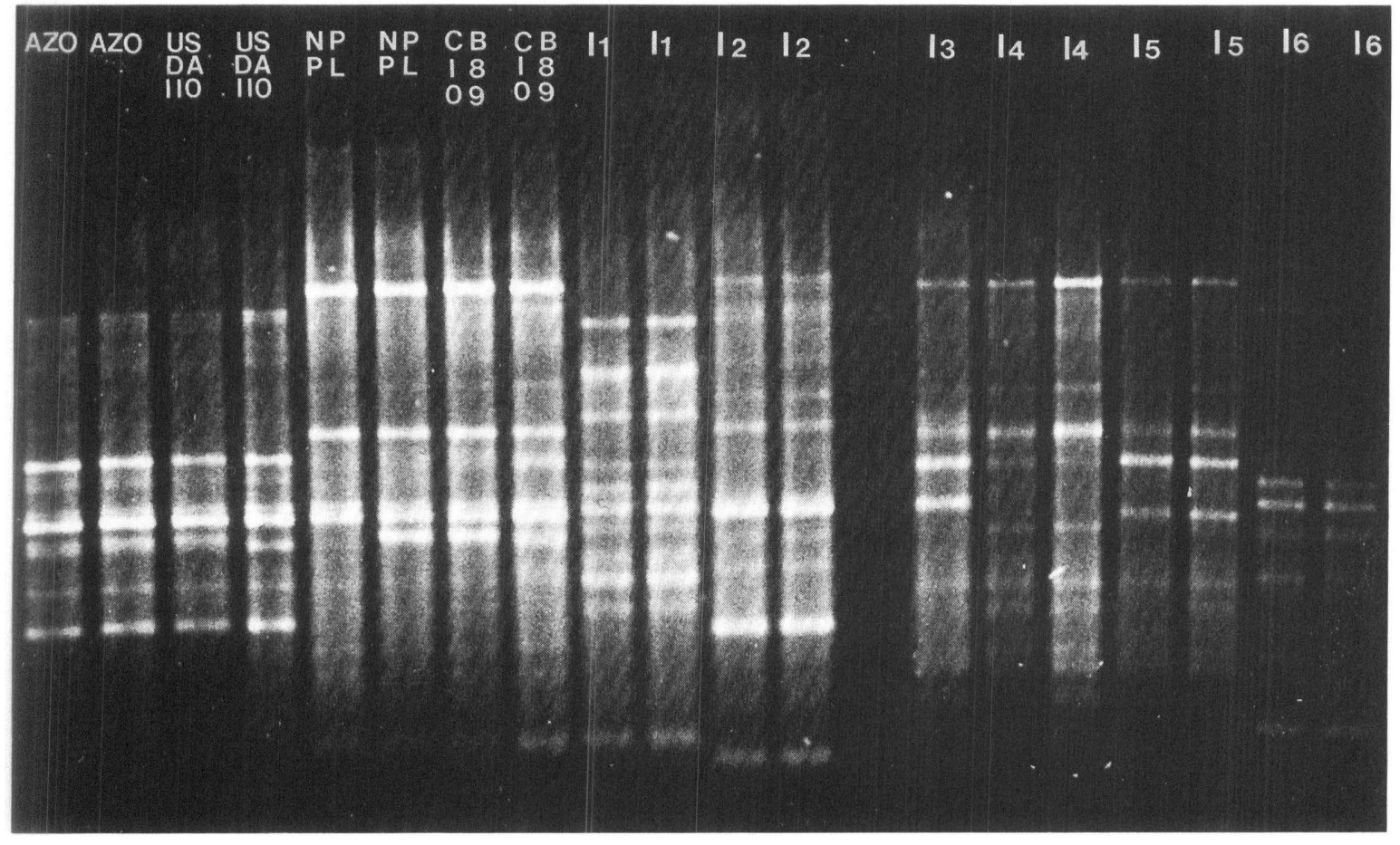

Fig. 1. RAPD fingerprint of inoculant strains. Lane number and strain: 1 and 2 , Azo; 3 and 4 , USDA110; 5 and 6, NPPL; 7 and 8, CB1809; 9 and 10,$11 ; 11$ and 12,$12 ; 13$, no sample; 14, 13; 15 and 16, 14; 17 and 18, 15; 19 and $20,16$.

Flury \& Riedwyl, 1988; Martens \& Naes, 1989), which is a wellknown technique for reducing the dimensionality of multivariate data whilst preserving most of the variance. Data were reduced by keeping only those principal components (PCs) whose eigenvalues accounted for more than $0.1 \%$ of the total variance. Canonical variates analysis $(\mathrm{CVA})$ then separated the samples into groups on the basis of the retained PCs and some a priori knowledge of the appropriate number of groupings (MacFice et al., 1978; Windig et al., 1983). The next stage was the construction of a percentage similarity matrix by transforming the Mahalanobis' distance between a priori groups in CVA using the Gower similarity coefficient $S_{G}$ (Gower, 1971). Finally, cluster analysis was employed to produce a dendrogram, using average linkage clustering (Gutteridge et al., 1985).

Ordination diagrams of the PYMS data were produced by plotting the eigenvalues derived from the canonical variate analyse's (Figs 2, 4 and 6). The first three axes usually accounted for between 92 and $97 \%$ of the total variation in the datasets and the simple two-dimensional representation was sufficient for demonstrating the relationship between the datapoints in multidimensional space.

RAPD. Bacteria from isolated colonies of 6 - $\mathrm{d}$-old cultures were lysed in proteinase $\mathrm{K}$ as described by Young \& Blakesley (1991). Samples (9 $\mu \mathrm{l}$ for each PCR reaction) were added to $16 \mu \mathrm{l}$ of the following reaction mixture: $10 \times$ Super-Taq reaction buffer (HT Biotechnology), $2.5 \mu \mathrm{l}$; dNTP mix (Pharmacia), $2.5 \mu \mathrm{l}$ of $2 \mathrm{mM}$ stock; primer P25 (5'-TATTTATTCCGGCCAATCATCCGC-3'), to a final concentration of $2 \mu \mathrm{M}$; Super-Taq (HT biotechnology) at 0.5 units per reaction (added last); ind water to give final volume. The lysate was mixed with the reaction mix in an Eppendorf tube and a drop of mineral oil (Sigma) added to the surface to prevent evaporation during the reaction.
Samples were placed in a thermal reactor (Hybaid) and run on the following programme with a temperature change regime of $1{ }^{\circ} \mathrm{C} \mathrm{s}^{-1}: 94{ }^{\circ} \mathrm{C}$ for $3 \mathrm{~min} ;\left(94{ }^{\circ} \mathrm{C}\right.$ for $45 \mathrm{~s} ; 30^{\circ} \mathrm{C}$ for $2 \min ; 72{ }^{\circ} \mathrm{C}$ for $2 \mathrm{~min}) \times 4$; $\left(94{ }^{\circ} \mathrm{C}\right.$ for $45 \mathrm{~s} ; 36^{\circ} \mathrm{C}$ for $1 \mathrm{~min} ; 72{ }^{\circ} \mathrm{C}$ for $2 \mathrm{~min}) \times 26 ; 72^{\circ} \mathrm{C}$ for $5 \mathrm{~min}$.

Samples were stored in a refrigerator and run on $1 \%(\mathrm{w} / \mathrm{v})$ agarose gels for separation of bands. These were visualized by staining with ethidium bromide $\left(50 \mu \mathrm{g} \mathrm{l}^{-1}\right)$ for $1 \mathrm{~h}$ and photographing the stained gels under UV light.

\section{RESULTS}

\section{Characterization of strains used in inoculants}

All inoculant strains were examined using PYMS and RAPD (Figs 1 and 2). The RAPD results show that different strains can be distinguished. Fortunately, for this study, the strain used in the Azofix inoculant (USDA110) was readily distinguished from strain CB1809 and the strains used in the Nitragin inoculant.

\section{Field A}

The recent cropping history of this field has been: 1982-1985 maize, 1986 beet, 1987-1989 soybeans. The soybeans were inoculated by seed dressing with inoculants in 1987, 1988 and 1989. In 1987 the inoculant was Nitragin. In 1988 and 1989 the inoculant was Azofix. In 1989 the field was examined to record nodulation by bradyrhizobia persisting from previous inoculations of soybean, which was excellent, and the population of 


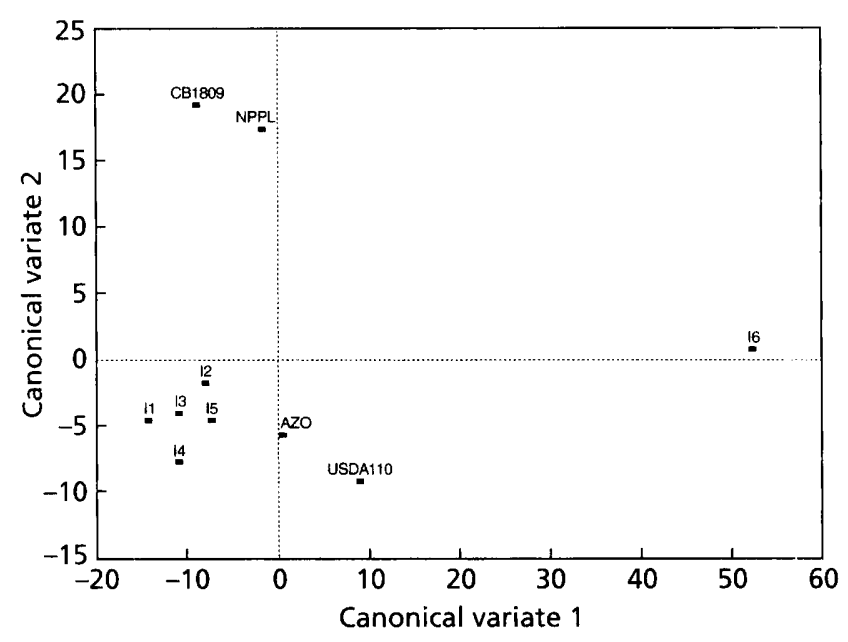

Fig. 2. PYMS of inoculant strains. Axes represent $92.85 \%$ of the total variation.

bradyrhizobia at the time of sowing, which was between 2 and $4 \times 10^{6}$ per $g$ soil on the basis of an MPN count.

Sample results for the determination of the different types of bradyrhizobia isolated from the field using RAPD and PYMS are shown in Figs 3 and 4. These results, and

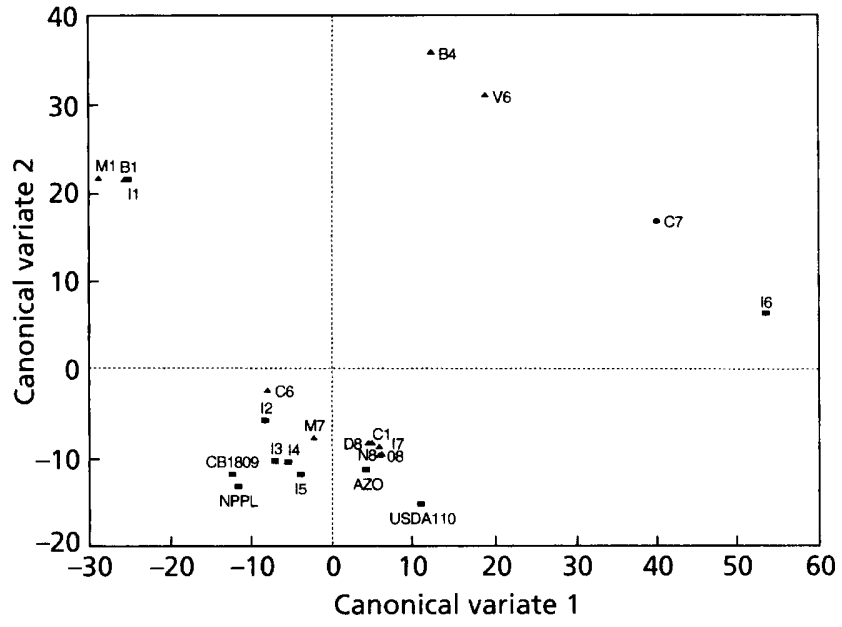

Fig. 4. PYMS of strains in Fig. 3. Axes represent $81.38 \%$ of the total variation. Triangles represent isolates; rectangles represent reference strains.

others not shown, found no isolate corresponding to that which should have been in the Azofix inoculum, even though it was the strain used in the inoculants for the year of sampling and the previous year. Examination of a

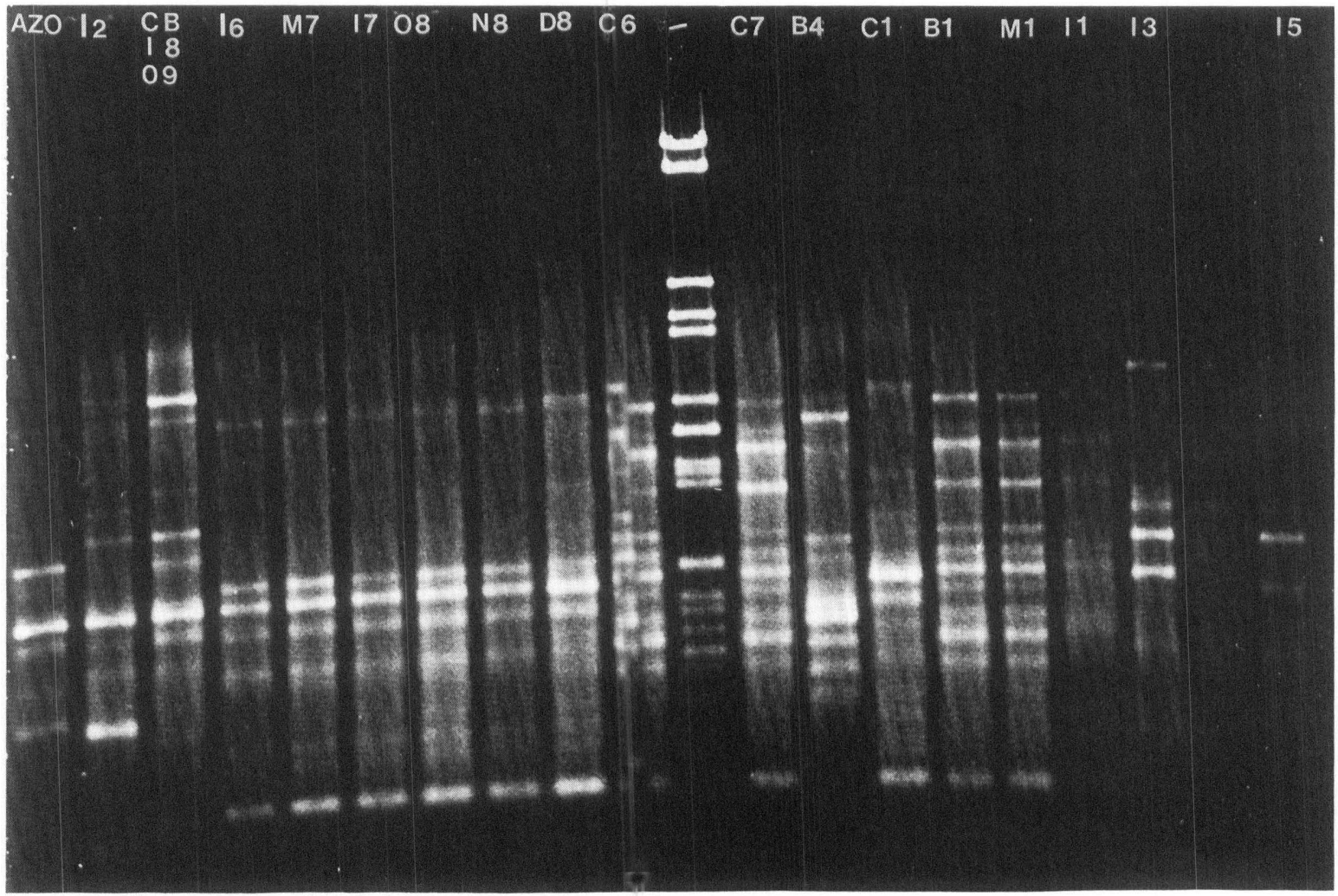

Fig. 3. RAPD of field $A$ isolates and standard strains. Larie number and strain: 1 , Azo; 2,$12 ; 3, C B 1809 ; 4$, 16; 5 , isolate $M 7 ; 6$, isolate $17 ; 7$, isolate $08 ; 8$, isolate $N 8 ; 9$, isolate $D 8 ; 10$, isolate $C 6 ; 11, \lambda$ Bg/l size marker; 12 , isolate $C 7 ; 13$, isolate $B 4 ; 14$, isolate $C 1 ; 15$, isolate $B 1 ; 16$, isolate $M 1 ; 17,11 ; 18,13 ; 20,15$. Lane 19 is too faint to use for characterization, probably because of a loading problem. 


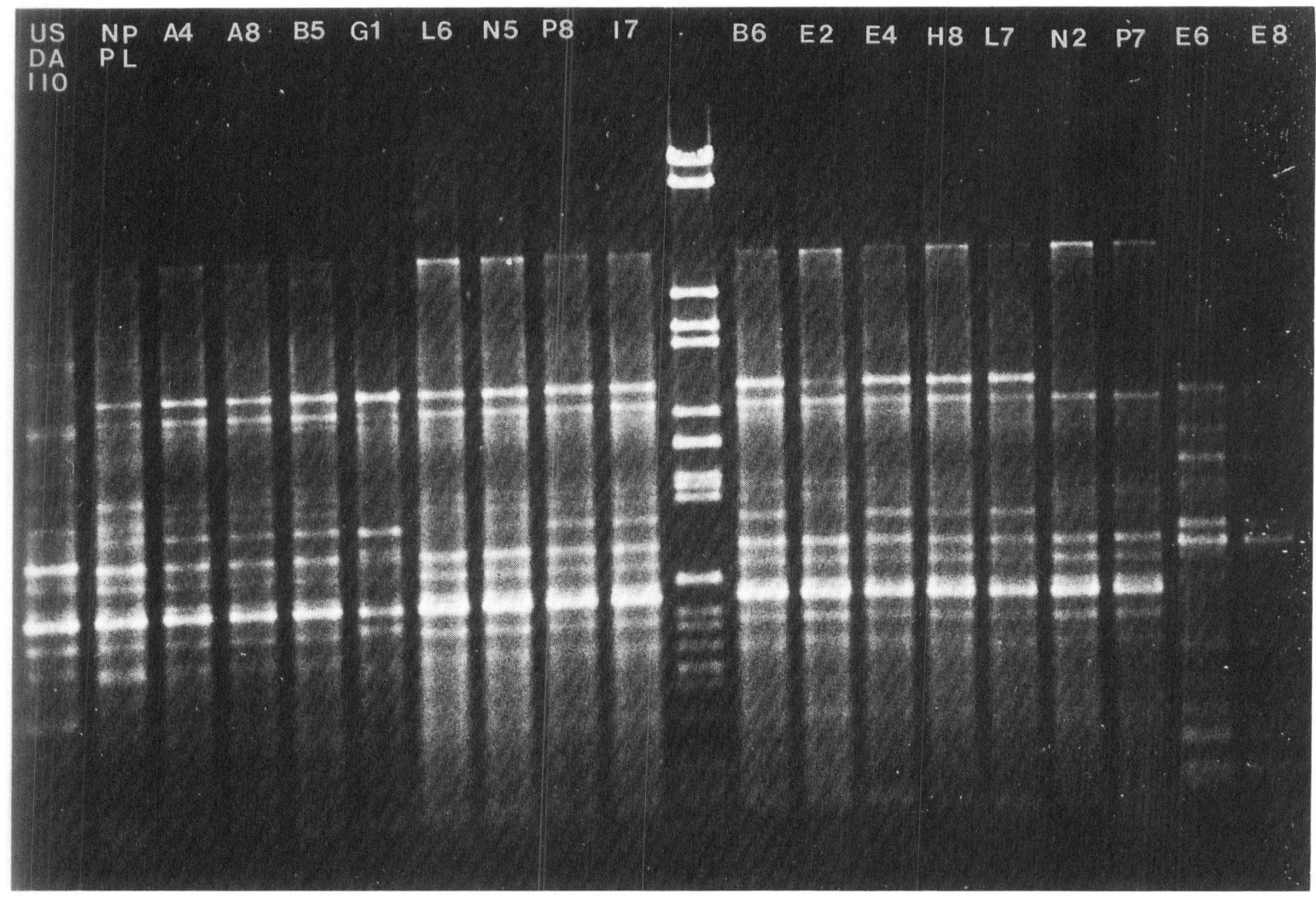

Fig. 5. RAPD of field $B$ isolates and standard strains. Lane number and strain: 1 , USDA $110 ; 2, N P P L ; 3, A 4 ; 4, A 8 ; 5, B 5 ; 6$, $\mathrm{G} 1 ; 7, \mathrm{~L} 6 ; 8, \mathrm{~N} 5 ; 9, \mathrm{P} 8 ; 10,17 ; 11, \lambda \mathrm{Bg} / \mathrm{I} ; 12, \mathrm{~B} 6 ; 13, \mathrm{E} 2 ; 14, \mathrm{E} 4 ; 15, \mathrm{H} 8 ; 16, \mathrm{~L} 7 ; 17$, N2; 18, P7; 19, E6; $20, \mathrm{E} 8$.

number of RAPD gels (not shown) indicated that some of the Nitragin strains were still present in the field. For example, in Fig. 3 isolates M7, I7 O8 and D8 appear to be derived from inoculant strain I6. PYMS analysis shows inoculant I6 to be very different from these isolates (Fig. 4), perhaps indicating genetic drift in the field, or that strain I6 used in the original inoculant was phenotypically different from our strain.

\section{Field B}

The recent cropping history of this field has been: 1983 sunflower, 1984 wheat, 1985 maize, 1986 soybeans, 1987 and 1988 maize, 1989 soybeans. The soybeans were inoculated by seed dressing with the Azofix inoculant in both 1986 and 1989. In this field, nodulation by bradyrhizobia remaining in the soil from previous inoculations of soybean was very good, even though no bradyrhizobia wert detected by MPN counting later in the year.

Analysis of bacteria isolated from nodules using RAPD and PYMS in no case showed any strain to be similar to strain USDA110 (Figs 5 and 6) even though this was the stratn we expected to find from the Azofix inoculant. By chance we included strain NPPL in these tests and found that most isolates had the same banding pattern using RAPD (Fig. 5). PYMS analysis (Fig. 6) showed that one group of isolates was very similar to NPPL and that there was another large group which was much less similar to it. Three strains, L6, A2 and N7, formed yet another small

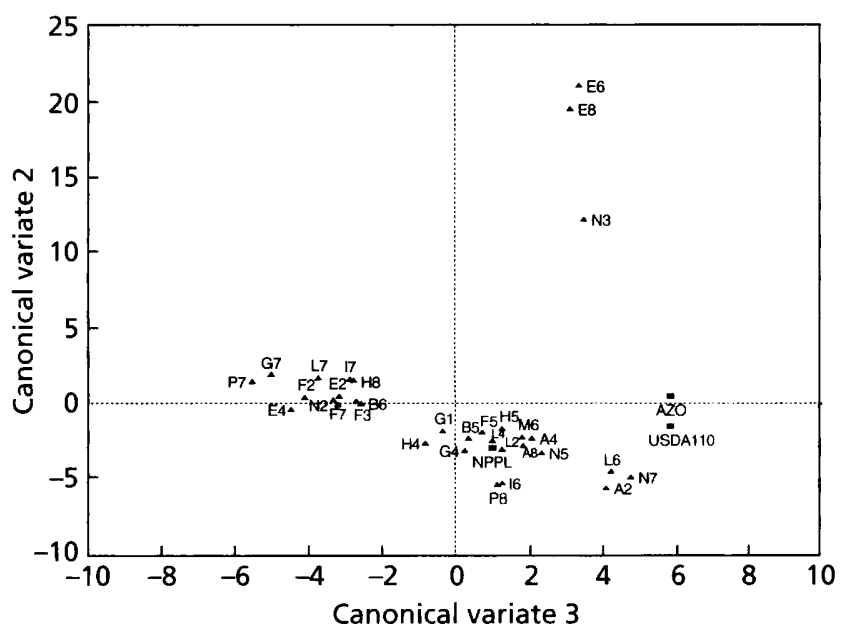

Fig. 6. PYMS of strains in Fig. 5. Axes represent $79.88 \%$ of the total variation. Symbols as in Fig. 4 .

group which were distinguishable from the main cluster around strain NPPL. Isolates E6 and E8 were found to be outliers in the PYMS analysis, and when analysed by RAPD were shown to be similar to each other but to have different banding patterns from the other strains tested. N3, the other outlier in PYMS, did not grow well and was lost before it could be studied further. 


\section{DISCUSSION}

Our results indicate that PYMS and RAPD can be used to discriminate strains of $B$. japonicum and have value in studying the fate of inoculants. The banding patterns produced by RAPD tend to show a number of bands in common between most strains, indicating that they are closely related. This relationship could be demonstrated by sequencing DNA from bands and using the sequenced DNA in hybridization assays to see whether the bands do indeed represent the same fragments of the genome. There was no need to demonstrate whether bands were the same or not in this study.

Both techniques have the advantage that hundreds of isolates can be analysed if required. Both have the disadvantage that they are very sensitive to the cultural state of the organisms concerned. We overcome this problem by making comparisons of organisms that are cultured on the same medium, under the same growth conditions at the same time, and do not assume that the techniques can be used to identify organisms without appropriate standard control strains cultured at the same time. The main advantage of the two techniques is that they allow us to determine if isolates are derivatives of the inoculum (RAPD), and if so whether they are phenotypically the same (PYMS). Fingerprints produced by RAPD are easy to generate and the cost per sample is low. PYMS analysis depends on expensive equipment, which limits its availability and means that the cost per sample is relatively high $(£, 1-2)$.

The choice of primer for PCR fingerprinting was entirely arbitrary; P25 was available in the laboratory, it works well, and gives a reasonable number of reproducible bands (Coutinho, 1993). The annealing conditions and other aspects of PCR fingerprinting are those which work well with bradyrhizobia in our laboratory. Our experience indicates that published procedures for species other than the one reported upon will need to be modified (Coutinho, 1993). For example, we have found that the age of colonies used for PCR is very important (Coutinho et al., 1993); young colonies (5 - $6 \mathrm{~d}$ old) of these slow-growing bacteria are ideal. As other workers have found (CaetanoAnolles et al., 1991, 1992; Young \& Blakesley, 1991; Mazurier et al., 1992; Brousseau et al., 1993) the amount of DNA, concentration of primers, method for preparing DNA and various other factors affect the efficiency with which strains can be discriminated (Coutinho, 1993).

Initially the results from the two fields studied were surprising because no bradyrhizobia isolated from them were like the strain we expected to find from the Azofix inoculant. Our results indicated that strain CB1809, or something very much like it, had been used as an inoculant in both fields. Further checking with the suppliers of the inoculant in Italy revealed that strain USDA110 had been replaced by CB1809 in Azofix inoculants used in Italy from 1986. This demonstrated the value of our techniques for characterizing inoculant strains.

Our analysis of strains from field B by PYMS indicated that there were three populations of $B$. japonicum. RAPD indicated that they were all the same as NPPL, which is the same as CB1809. We assume that the PYMS analysis is showing change as a result of natural selection in the soil, although it cannot be excluded that it represented three populations present in the initial inoculum. An exciting challenge facing microbial ecologists in the immediate future is to find ways of identifying which characteristics change during adaptation, and why.

\section{ACKNOWLEDGEMENTS}

We would like to thank Clive Hetherington (University of Newcastle-upon-Tyne) for excellent technical assistance with the PYMS analyses, Dr Colin Lazarus (University of Bristol) for help in developing RAPD assays, and Professor Douglas Kell (University of Wales) for his help. This work was supported by the following grants: EEC CI1* 0545-UK (J.E.B. and H. L.C.C.), EEC BIOT-CT91-0283 (J.E.B. and H.K.), EEC BAP-0380-UK (J.E.B. and H.K.), and SERC Biotechnology Directorate LINK scheme in Biochemical Engineering in collaboration with Horizon Instruments, Neural Computer Sciences and Zeneca Ltd (R.G.).

\section{REFERENCES}

Aries, R. E., Gutteridge, C. S. \& Ottley, T. W. (1986). Evaluation of a low-cost, automated pyrolysis-mass spectrometer. I Anal Appl Pyrolysis 9, 81-98.

Beringer, J. E., Ruiz Sainz, J. E. \& Johnston, A. W. B. (1984). Methods for the genetic manipulation of Rhizobium. In Microbial Methods for Environmental Biotechnology (Society for Applied Bacteriology Technical Series 19), pp. 79-94. Edited by J. M. Grainger \& J. M. Lynch. London: Academic Press.

Brousseau, R., Saint-Onge, A., Préfontaine, G., Masson, L. \& Cabana, J. (1993). Arbitrary primer polymerase chain reaction, a powerful method to identify Bacillus thuringiensis serovars and strains. Appl Environ Microbiol 59, 114119.

Caetano-Anolles, G., Bassam, B. J. \& Gresshoff, P. M. (1991). DNA amplification fingerprinting using very short arbitrary oligonucleotide primers. Bio/Technology 9, 553-557.

Caetano-Anolles, G., Bassam, B. J. \& Gresshoff, P. M. (1992). DNA amplification fingerprinting with very short primers. In Applications of RAPD Technology to Plant Breeding. Joint Plant Breeding Symposia Series. Minnesota: Crop Science Society of America.

Causton, D. R. (1987). A Biologist's Advanced Mathematics, pp. 48-72. London: Allen \& Unwin.

Chatfield, C. \& Collins, A. J. (1980). Introduction to Multivariate Analysis, pp. 57-81. London: Chapman \& Hall.

Coutinho, H. L. C. (1993). Studies of bradyrhizobia from the Brazilian Cerrados. PhD thesis, University of Bristol.

Coutinho, H., Handley, B. A., Kay, H. E., Stevenson, L. \& Beringer, J. E. (1993). The effect of colony age on PCR fingerprinting. Lett Appl Microbiol 17, 282-284.

Dudman, W. (1971). Antigenic analysis of Rhizobium japonicum by immunodiffusion. Appl Microbiol 21, 973-985.

Flury, B. \& Riedwyl, H. (1988). Multivariate Statistics: a Practical Approach, pp. 181-233. London: Chapman \& Hall.

Goodacre, R. \& Berkeley, R. C. W. (1990). Detection of small genotypic changes in Escherichia coli by pyrolysis mass spectrometry. FEMS Microbiol Lett 71, 133-138.

Goodacre, R., Berkeley, R. C. W. \& Beringer, J. E. (1991a). The use of pyrolysis-mass spectrometry to detect the fimbrial adhesive 
antigen $\mathrm{F} 41$ from Escherichia coli HB101(pSLM204). J Anal Appl Pyrolysis 22, 19-28.

Goodacre, R., Hartmann, A., Beringer, J. E. \& Berkeley, R. C. W. (1991b). The use of pyrolysis mass spectrometry in the characterisation of Rbizobium meliloti. Lett Appl Microbiol 13, 157-160.

Gower, J. C. (1971). A general coefficient of similarity and some of its properties. Biometrics 27, 857-874.

Gutteridge, C. S. (1987). Characterisation of microorganisms by pyrolysis mass spectrometry. Metbods Microbiol 19, 227--272.

Gutteridge, C. S., Vallis, L. \& MacFie, H. J. H. (1985). Numerical methods in the classification of microorganisms by pyrolysis mass spectrometry. In Computer-Assisted Bacterial Systematics, pp. 369-401. L dited by M. Goodfellow, D. Jones \& F. Priest. London: Academic Press.

Hartmann, A., Catroux, G. \& Amarger, N. (1992). Bradyrbizobium japonicum strain identification by RFLP analysis using the repeated sequence RSx. Lett Appl Microbiol 15, 15-19.

Kamicker, B. J. \& Brill, W. J. (1986). Identification of Bradyrbizobium japonicum nodule isolates from Wisconsin soybean farms. Appl Environ Microbiol 51, 487-492.

MacFie, H. J. H. \& Gutteridge, C. S. (1982). Comparative studies on some methods for handling quantitative data generated by pyrolysis. J 4nal Appl Pyrolysis 4, 175-204.

MacFie, H. J. H., Gutteridge, C. S. \& Norris, J. R. (1978). Use of canonical variates in differentiation of bacteria by pyrolysis gasliquid chromatography. J Gen Microbiol 104, 67-74.

Martens, H. \& Naes, T. (1989). Multivariate Calibration. New York: John Wiley \& Sons.

Mazurier, S.-I., Audurier, A., Marquet-van der Mee, N., Notermans, S. \& Werners, K. (1992). A comparative study of randomly amplified polymorphic DNA analysis and conventional phage typing for epidemiological studies of Listeria monocytogenes isolates. Res Microbiol 143, 507-512.

Meuzelaar, H. L. C., Haverkamp, J. \& Hileman, F. D. (1982). Pyrolysis Mass Spectrometry of Recent and Fossil Biomaterials. Amsterdam: Elsevier.

Mielenz, J. R., Jackson, L. E., O'Gara, F. \& Shanmugam, K. T. (1979). Fingerprinting bacterial chromosomal DNA with restriction endonuclease EcoRI: comparison of Rbizobium spp. and identification of mutants. Can J Microbiol 25, 803-807.

Regensburger, B. \& Hennecke, H. (1983). RNA polymerase from Rbizobium japonicum. Arch Microbiol 135, 103-109.

Vincent, J. M. (1970). A Manual for the Practical Study of the Root Nodule Bacteria. (IBP Handbook no. 15). Oxford: Blackwell.

Williams, J. G. K., Kubelik, A. R., Livak, K. J., Rafalski, J. A. \& Tingey, S. V. (1990). DNA polymorphisms amplified by arbitrary primers are useful as genetic markers. Nucleic Acids Res 18, 6531-6535.

Windig, W., Kistemaker, P. G. \& Haverkamp, K. (1979). The effects of sample preparation, pyrolysis and pyrolysate transfer on pyrolysis mass spectra. J Anal Appl Pyrolysis 1, 39-52.

Windig, W., Haverkamp, J. \& Kistemaker, P. G. (1983). Interpretation of a set of pyrolysis mass spectra by discriminant analysis and graphical rotation. Anal Chem 55, 387-391.

Young, A. \& Blakesley, R. (1991). Sequencing plasmids from single colonies with the dsDNA cycle sequencing system. Focus 13, 13.

Received 8 November 1993; revised 28 March 1994; accepted 28 April 1994. 